\title{
Histopathological Study of Gastric Lesions and its Correlation with Mucin Histochemistry and Helicobacter Pylori Infection
}

\author{
Alankrita Deka ${ }^{1 *}$, Adity Sharma², Ratna K Bhuyan ${ }^{3}$ and Sanjay LN Paul ${ }^{4}$ \\ ${ }^{1}$ State cancer institute, GMCH, Guwahati, Assam \\ ${ }^{2}$ Department of Pathology, AMCH, Dibrugarh, Assam \\ ${ }^{3}$ Department of Surgery, AMCH, Dibrugarh, Assam
}

\section{ABSTRACT}

Background: Gastric disorders are responsible for a great deal of mortality and morbidity and are one of the most common encountered problems in clinical practice. H. Pylori infection is responsible for majority of acid peptic disease and is also a known carcinogen. Intestinal metaplasia is considered a precancerous lesion. We studied the incidence of H. pylori infection and mucin histochemistry of different gastric lesions.

Methods: This study was conducted for a period of 1 year, in 50 gastric specimens received for histopathological study in the Department of Pathology, AMCH. Slides were stained with routine H\&E and Giemsa for H. pylori detection. PAS/AB stain (at pH 2.5 \& $\mathrm{pH} 1.0)$ was done to study mucin histochemistry.

Results: Out of 50 cases, $58 \%$ cases were malignant and $42 \%$ cases were benign. H. Pylori was seen in $42 \%$ cases. IM was observed in $40 \%$ of gastric lesions. IM was more common in malignant lesions. On subclassification, Type 1 and 2 IM were seen almost equally in both benign and malignant gastric lesions, but Type $3 \mathrm{IM}$ was more common in malignant lesion. Incidence of IM was higher in intestinal than diffuse adenocarcinoma. A statistically significant association was seen between H. Pylori infection and IM.

Conclusion: Routine detection of H. pylori by special stains and mucin study in all gastric biopsy specimens helps in early detection of precancerous gastric lesions.

Keywords: Gastric Lesions, Helicobacter Pylori Infection, Mucin Staining, Intestinal Metaplasia

\section{Introduction}

Stomach is a common site for inflammatory and neoplastic lesions. ${ }^{[1]} \mathrm{H}$. pylori infection is an important step of gastric carcinogenesis cascade ${ }^{[2]}$, resulting changes from chronic gastritis, atrophic change and intestinal metaplasia to gastric cancer. Study of mucin histochemistry has been used to characterize the transformations of normal gastric epithelium leading to intestinal metaplasia and to carcinoma. ${ }^{[3]}$ Objective of this study is to detect incidence of H-pylori infection, study mucin histochemistry and the histopathology of gastric lesions.

\section{Materials and Methods}

The study was conducted in the department of Pathology, AMCH for a period of 1 year from June 2017 to May 2018. 50 gastric tissue including both endoscopic biopsy and gastrectomy specimens of both benign and malignant gastric disease were included. Tissue sent for histopathology was processed and routinely stained with $\mathrm{H} \& \mathrm{E}$. Giemsa staining was done to detect $\mathrm{H}$. pylori. $\mathrm{AB} / \mathrm{PAS}$ staining was done at $\mathrm{pH} 2.5$ to differentiate neutral mucin from acidic mucin \& $\mathrm{pH} 1.0$ to differentiate sialomucin from sulphomucin.

\section{Result}

Out of 50 cases, 44 were endoscopic biopsies and 6 were gastrectomy specimens. Majority of patients were from 41 to 70 years. Male to female ratio was $1.5: 1.42 \%$ (21) cases were benign and 58\% (29) cases were malignant. Most common benign lesion was chronic gastritis 33.33\% and most common gastric carcinoma was MDADC 50 $\%$. Distribution of gastric lesion based on histopathology shown in table 1.

H. Pylori was detected by Giemsa staining in $21(42 \%)$ cases out of 50 . Of which $08(38.09 \%)$ were malignant and $13(61.91 \%)$ were benign. Table 2 shows incidence of $\mathrm{H}$. Pylori positive cases in different gastric lesions. IM was seen in $20(40 \%)$ cases out of 50 by $\mathrm{AB} / \mathrm{PAS}$ staining. $12(60 \%)$ were malignant and $08(40 \%)$ were benign lesions. Table 3 shows distribution of IM in different gastric lesions. Type 1 and 2 IM was equally seen in both benign and malignant gastric lesions, but sulphomucin positive Type 3 intestinal metaplasia was seen in only $25 \%$ benign lesion and $75 \%$ malignant lesion. 
Out of 20 IM positive cases, $14(70 \%)$ cases showed H. pylori infection. Statistically significant association was seen between IM and H. Pylori infection ( $\mathrm{p}$ value 0.001 by Fischer exact test).

\section{Discussion}

Although incidence of gastric carcinoma is on decline but still it remains the fourth most commonly diagnosed cancer

Table 1: Distribution of gastric lesions based on histopathological diagnosis.

\begin{tabular}{|l|l|l|l|}
\hline Category & Histopathological diagnosis & Frequency & Percentage \\
\hline \multirow{4}{*}{ Benign lesions } & Chronic gastritis & 07 & $14 \%$ \\
\cline { 2 - 4 } & Gastric ulcer & 05 & $10 \%$ \\
\cline { 2 - 4 } & Hyperplastic polyp & 03 & $6 \%$ \\
\cline { 2 - 4 } & Dysplasia & 06 & $12 \%$ \\
\hline \multirow{5}{*}{$\begin{array}{l}\text { Malignant } \\
\text { lesions }\end{array}$} & Well differentiated ADC & 07 & $14 \%$ \\
\cline { 2 - 4 } & Moderately differentiated ADC & 12 & $24 \%$ \\
\cline { 2 - 4 } & Poorly differentiated ADC & 05 & $10 \%$ \\
\cline { 2 - 4 } & Mucinous adenocarcinoma & 02 & $4 \%$ \\
\cline { 2 - 4 } & Signet ring cell carcinoma & 02 & $\mathbf{4} \%$ \\
\cline { 2 - 4 } & Squamous Cell carcinoma & 01 & $\mathbf{2 \%}$ \\
\cline { 2 - 4 } & TOTAL & $\mathbf{5 0}$ & $\mathbf{1 0 0} \%$ \\
\hline
\end{tabular}

Table 2: Incidence of H. Pylori positive cases by Giemsa staining in different gastric lesions.

\begin{tabular}{|l|l|l|}
\hline Histology diagnosis & H. Pylori positive & Percentage \\
\hline Chronic gastritis & 03 & $14.29 \%$ \\
\hline Gastric ulcer & 05 & $23.81 \%$ \\
\hline Hyperplastic polyp & 02 & $9.52 \%$ \\
\hline Dysplasia & 03 & $14.29 \%$ \\
\hline WD ADC & 03 & $14.29 \%$ \\
\hline MD ADC & 04 & $19.05 \%$ \\
\hline PD ADC & 01 & $4.76 \%$ \\
\hline Mucinous ADC & 00 & $0 \%$ \\
\hline Signet ring cell ca & 00 & $0 \%$ \\
\hline SCC & 00 & $0 \%$ \\
\hline TOTAL & $\mathbf{2 1}$ & $\mathbf{1 0 0} \%$ \\
\hline
\end{tabular}

Table 3: Distribution of Intestinal Metaplasia in gastric lesions based on Alcian blue/PAS staining at pH 2.5 and pH 1.0.

\begin{tabular}{|l|l|l|l|l|l|}
\hline Histopathological diagnosis & \multicolumn{2}{l}{ No. of specimen } & \multicolumn{3}{l|}{ Sub types of IM } \\
\hline & All & IM $\%$ & Type 1 & Type 2 & Type 3 \\
\hline Chronic gastritis & 07 & $2(28.57 \%)$ & $1(50 \%)$ & $1(50 \%)$ & - \\
\hline Gastric ulcer & 05 & $3(60 \%)$ & $1(33.3 \%)$ & $1(33.3 \%)$ & $1(33.3 \%)$ \\
\hline Hyperplastic polyp & 03 & $1(33.3 \%)$ & - & $1(100 \%)$ & - \\
\hline Dysplasia & 06 & $2(33.33 \%)$ & $1(50 \%)$ & $1(50 \%)$ & - \\
\hline WD ADC & 07 & $3(42.85 \%)$ & - & $2(66.67 \%)$ & $1(33.33 \%)$ \\
\hline MD ADC & 12 & $4(33.33 \%)$ & $1(25 \%)$ & $2(50 \%)$ & $1(25 \%)$ \\
\hline PD ADC & 05 & $2(40 \%)$ & - & $1(50 \%)$ & $1(50 \%)$ \\
\hline Mucinous ADC & 02 & $1(50 \%)$ & - & $1(100 \%)$ & - \\
\hline Signet ring cell ca & 02 & $2(100 \%)$ & $1(50 \%)$ & $1(50 \%)$ & - \\
\hline SCC & 01 & - & - & - & - \\
\hline Total & $\mathbf{5 0}$ & $\mathbf{2 0 ( 3 5 \% )}$ & $\mathbf{0 5}(\mathbf{2 5} \%)$ & $\mathbf{1 1 ( 5 5 \% )}$ & $\mathbf{0 4}(\mathbf{2 0} \%)$ \\
\hline
\end{tabular}


Table 4: Distribution of sub types of IM in intestinal \& diffuse type of gastric carcinoma.

\begin{tabular}{|l|l|l|l|l|l|l|}
\hline \multirow{2}{*}{ Study } & \multicolumn{4}{l|}{ Intestinal type } & \multicolumn{2}{l|}{ Diffuse } \\
\cline { 2 - 7 } & No. cases & Type 1 \& 2 IM\% & Type 3 IM \% & No. cases & Type 1 \& 2 IM\% & Type 3 IM \% \\
\hline Jass et al. ${ }^{[23]}$ & 23 & 26.1 & 73.9 & 7 & 100 & 0 \\
\hline Jass Filipe et al. ${ }^{[24]}$ & 24 & 25 & 75 & 6 & 100 & 0 \\
\hline Segura DI Montero C et al. ${ }^{[25]}$ & 19 & 11 & 89 & 14 & 65 & 35 \\
\hline Rehman et al. (2016) ${ }^{[26]}$ & 13 & - & - & 3 & - & - \\
\hline Present & 21 & 75 & 25 & 8 & 100 & 0 \\
\hline
\end{tabular}

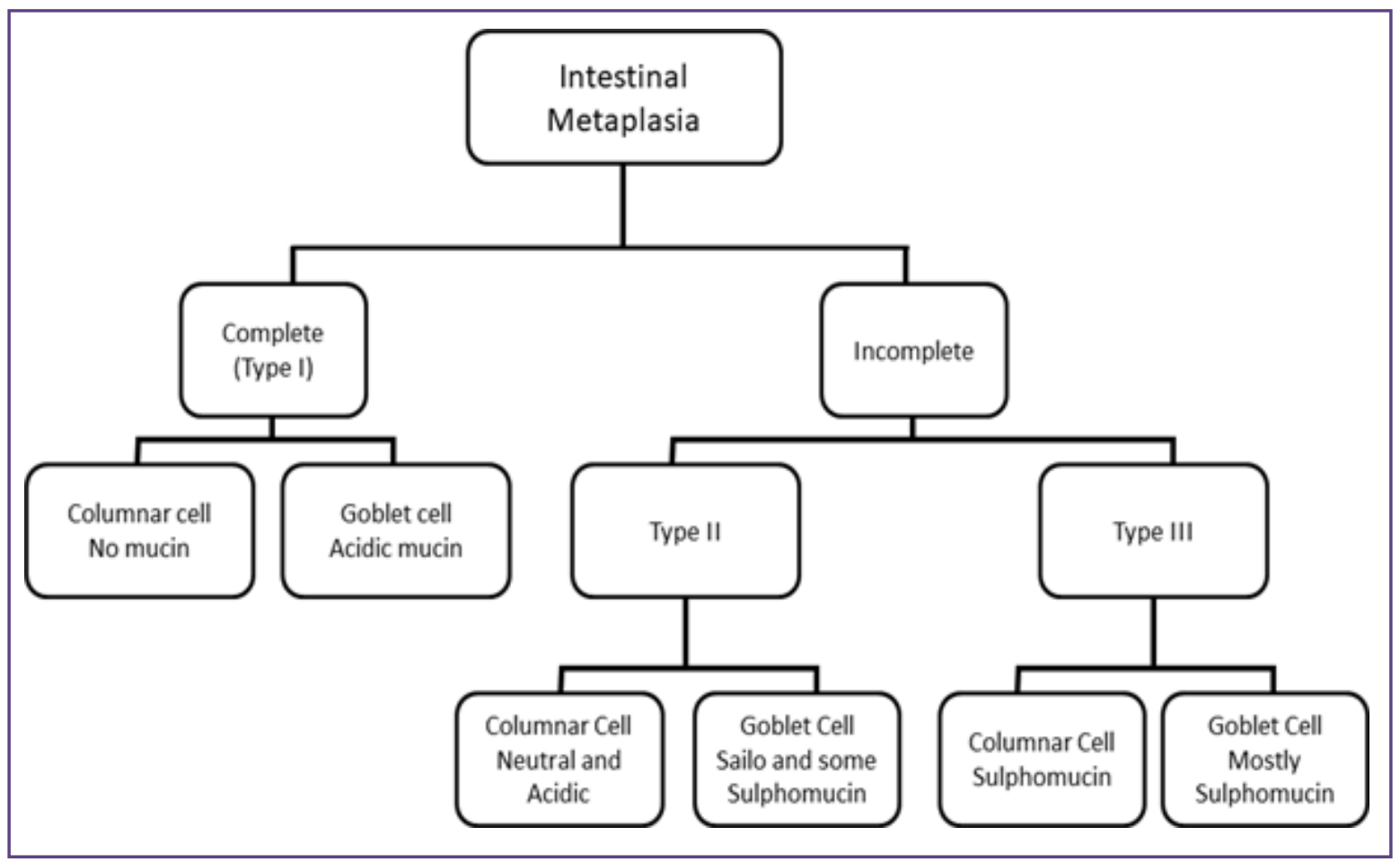

Fig. 1: Based on the mucin detection gastric intestinal metaplasia can be divided into 3 subtypes [18, 22, 23].

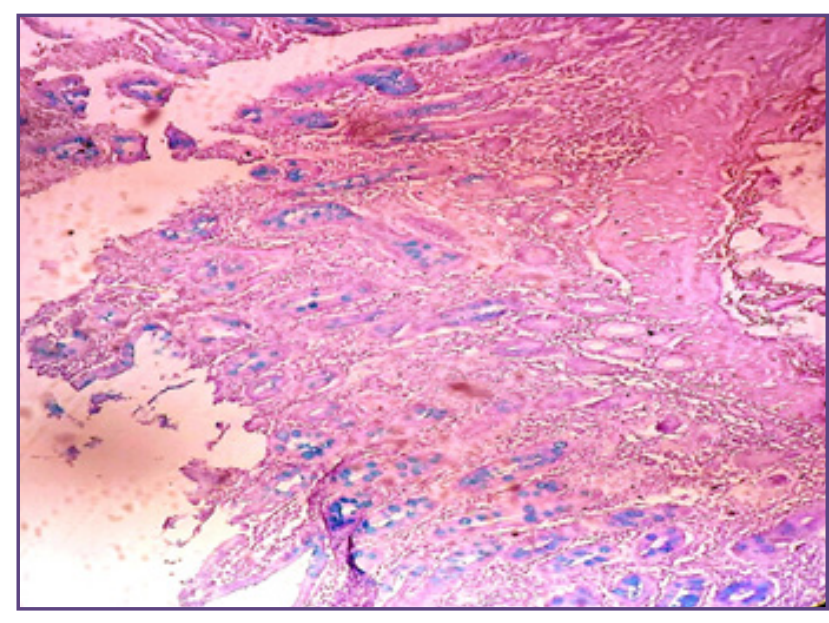

Fig. 2 : Photomicrograph of Type 1 IM, showing sialomucin in the goblet cells (Alcian blue/PAS at pH $2.540 \mathrm{X}$ ).

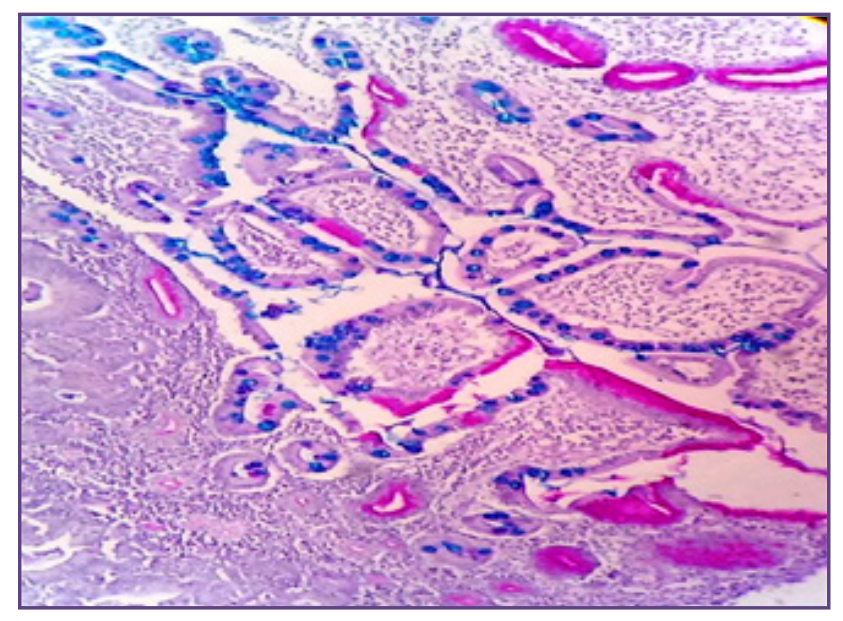

Fig. 3 : Photomicrograph of Type 2 IM, showing mostly sialomucin in goblet cells, along with neutral mucin in columnar cells (Alcian blue/PAS at pH 2.5,10X) 


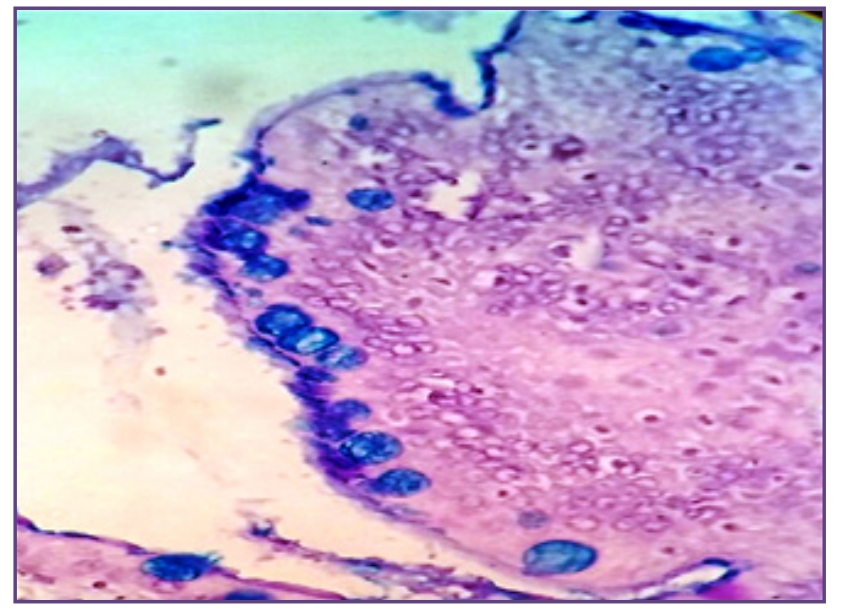

Fig. 4: Photomicrograph of Type 3 IM, showing sulphomucin secreting columnar cells Alcian blue/PAS at pH 1.0.

${ }^{[4]}$ and second most common cause of cancer related death in the world ${ }^{[5]}$. The rates for gastric cancer in North-eastern registries are higher than that of rest of the country ${ }^{[6]}$.

Helicobacter Pylori has been implicated as an important etiological factor in gastric carcinoma through its role in the development of chronic gastritis. H. Pylori infection is an important initiating and promoting step of this gastric carcinogenesis cascade ${ }^{[2]}$. Hence, it is necessary to detect H. Pylori routinely in all gastric lesions.

H. Pylori is a gram negative, microaerophilic, urease positive, curved, motile bacterium that resides in the gastric pits and the overlying mucus blanket ${ }^{[7]}$. There are number of methods of detecting H. pylori, but the histological detection in a gastric biopsy is the commonest and among the most sensitive ${ }^{[8]}$. Effective antimicrobial treatment depends on sensitive and accurate diagnostic approaches [9]. Therefore, there is great interest in the detection and eradication of this bacterium for good prognostic outcome.

The distribution and number of mucins varies in different regions of the GIT. The mucosa of the stomach has been found to have some qualitative as well as quantitative changes in the non-neoplastic and neoplastic lesions compared to normal mucosa by mucin histochemistry ${ }^{[10]}$. Neutral mucins present in normal mucosa gradually decrease during the initial development of IM, while sialomucins appear and become predominant. In more advanced stages, sulfomucins appear and may become predominant ${ }^{[11]}$.

Based on the mucin secretion \& cell differentiation, three types of intestinal metaplasia can be recognized in the stomach i.e., Type I (complete), Type II (incomplete) and type III (incomplete) ${ }^{[12]}$. Intestinal metaplasia (IM) has been observed in various gastric lesions like gastric cancer,

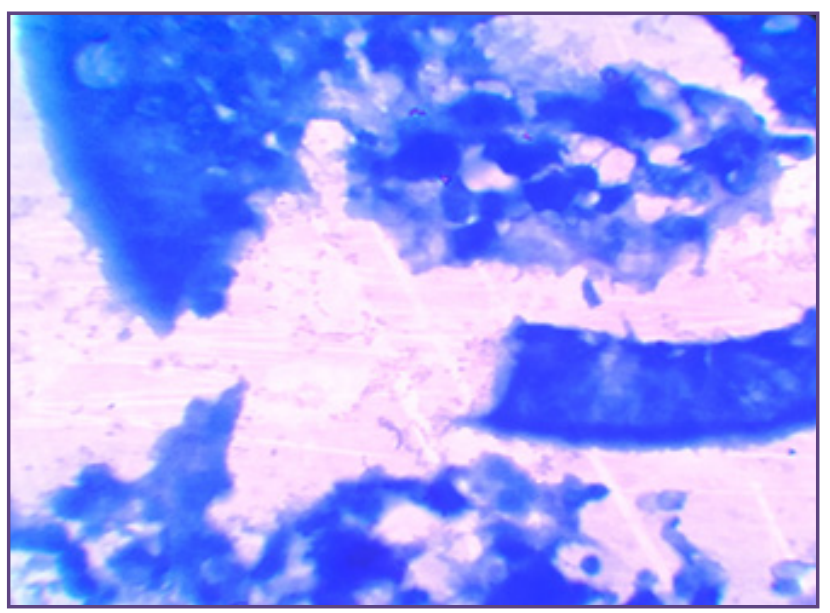

Fig. 5: Photomicrograph showing H. pylori in Giemsa stain (100X).

gastric ulcer and atrophic gastritis. Studies have indicated a close relation between sulphomucin secreting Intestinal Metaplasia type III and intestinal type of gastric carcinoma [3]. It is considered to be a precancerous lesion before development of dysplasia in the evolution of Intestinal type of gastric carcinoma.

Thus, simultaneous assessment of histopathology and mucin histology at the time of initial diagnosis can provide a beneficial role in early diagnosis and individual therapeutic strategies.

Maximum cases were in 41 to 70 years (68\%) comparable to Monika Bansal el al. ${ }^{[8]}$ study. In our present study, 58\% cases were malignant lesions and $42 \%$ cases were benign lesions. Thapa R et al. (2013) ${ }^{[13]}$ in their study noted that $32.5 \%$ cases were neoplastic lesions and $67.5 \%$ cases were non-neoplastic lesions. Malignant lesions were more comparable to the other studies this could be supported by the fact that in our study both endoscopy biopsies and gastrectomy specimens were taken. In our study the most common site of gastric lesion was antrum (58\%) its less compared to study conducted by UDOH M O et al. (2012) ${ }^{[14]}$ where $63.2 \%$ gastric lesions were from antrum. Most common clinical feature in our study was dyspepsia (70\%) comparable to study conducted by Shanmugasamy K et al. (2016) ${ }^{[15]}$ where most common presenting feature was also dyspepsia.

Similar to our study most common non neoplastic lesion was chronic gastritis $44 \%$ in Shanmugasamy K et al. ${ }^{[15]}$ study. Most common gastric carcinoma were MDADC in Thapa $\mathrm{R}$ et al. ${ }^{[13]}$ study which is in accordance with our study. Incidence of H. Pylori positivity in our study (42\%) was in accordance to Dandin AS et al. ${ }^{[16]}$ study (43\%). In our study, percentage of $\mathrm{H}$. Pylori infection in gastric 
carcinoma (27.59\%) was comparable to study conducted by Sultana A et al. (2011) ${ }^{[9]}(27.0 \%)$ but lower than Bansal $\mathrm{M}$ et al. ${ }^{[8]}$ study (33.3\%). Percentage of H. Pylori infection in chronic gastritis $(42.86 \%)$ was lower in our study compared to A. Sultana et al. ${ }^{[9]}(60 \%)$ and Bansal M et al. ${ }^{[8]}(56.7 \%)$. Percentage of $\mathrm{H}$. Pylori infection in gastric ulcer $(100 \%)$ was equivalent to study conducted by Bansal $\mathrm{M}$ et al. (2017) ${ }^{[8]}(100 \%)$ but lower than A. Sultana et al. ${ }^{[9]}$ study $(50 \%)$.

Our study shows statistically significant association between $\mathrm{H}$. Pylori infection and gastric ulcer ( $\mathrm{p}$ value 0.009 ) and gastric carcinoma ( $\mathrm{p}$ value 0.021 ) [p value $<0.005$ was considered statistically significant]. But no statistically significant association was seen between $\mathrm{H}$. Pylori infection and chronic gastritis in our study.

IM was seen in $40 \%$ cases comparable to $35 \%$ in Einstien D et al. ${ }^{[17]}$ study. In our present study incidence of intestinal metaplasia in malignant lesion was seen in $12(41.38 \%)$ cases and in benign lesions was seen in $8(38.09 \%)$ cases. It is comparable to Einstein D et al. ${ }^{[17]}$ study $30.1 \%$ \& $64.7 \%$ respectively. In our study type I and II intestinal metaplasia in malignant lesion was seen in $75 \%$ cases and type III IM was seen in $25 \%$ cases which is in accordance with Mandal et al. $2013^{[18]}$ study ( $78.3 \%$ and $17.4 \%$ respectively). And in benign lesion type I and type II IM is seen in $87.5 \%$ and type III in $12.5 \%$ which is in accordance with Rothery, Day et al. ${ }^{[19]} 84.7 \%$ and $15.3 \%$.

Distribution of sub types of IM in intestinal \& diffuse type of gastric carcinoma is shown in table 5. It is evident that the incidence of type $3 \mathrm{IM}$ is more common in intestinal type of gastric adenocarcinoma than in diffuse type of gastric adenocarcinoma and is in accordance with our study.

In our study out of 50 cases, 20 cases showed IM out of which $70 \%$ cases were associated with $\mathrm{H}$. pylori infection and $30 \%$ cases showed no H. pylori infectivity.

Statistically significant association ( $p$ value 0.001 ) has been found between H. Pylori infection and IM in our study ( $\mathrm{p}$ value $<0.05$ is considered significant). Compared to study conducted by M E Craanen et al. (1992) ${ }^{[20]}$ where 33.9\% cases of IM were associated with H. Pylori and 15.2\% cases of IM was not associated with $\mathrm{H}$. Pylori, $\mathrm{p}<0.001$. In study conducted by Sheng Quan et al. (2017) ${ }^{[21]}$; significant statistical correlation has been found between H. Pylori infection and IM, p value $0.038(<0.05$ is significant $)$.

\section{Conclusion}

$\mathrm{H}$. Pylori infection is seen to be associated with varieties of gastric lesions. It is a known carcinogen. Hence, early detection can halt the cascade and improve prognosis. And use of special stain like Giemsa significantly improves the diagnosis of H. Pylori.

Presence of type 3 intestinal metaplasia in benign gastric lesions needs to be closely followed up endoscopically because they possess more risk of developing intestinal type of gastric adenocarcinoma.

\section{Acknowledgement}

Authors are grateful to Head of Department, Pathology for giving permission to conduct the study.

\section{Funding}

Nil

\section{Competing Interests}

The authors declare that there is no conflict of interest

\section{Abbreviations}

ADC : Adenocarcinoma; WDADC : Well differentiated adenocarcinoma ; MDADC : Moderately differentiated adenocarcinoma ; PDADC : Poorly differentiated adenocarcinoma ; H. pylori : Helicobacter pylori ; PAS: Periodic acid Schiff ; AB : Alcian blue ; IM : Intestinal Metaplasia ; H\&E: Haematoxylin \& Eosin.

\section{References}

1. Krishnappa R, Horakerappa Ms, Ali K, Gouri M. A Study On Histopathological Spectrum Of Upper Gastrointestinal Tract Endoscopic Biopsies. Int J Med Res Health Sci 2013;2(3):418-24.

2. Liu KSH, Wong IOL, Leung WK. Helicobacter pylori associated gastric intestinal metaplasia: Treatment and surveillance. World J Gastroenterol 2016; 22(3): 1311-1320.

3. Ganesh IM, Subramani D, Halagowder D. Mucin glycoarray in gastric and gallbladder epithelia. J Carcinog [serial online] 2007 [cited 2021 Feb 18];6:10.

4. Manasa G C, Sunila, Manjunath Gv, Histopathological study of gastric carcinoma with associated precursor lesions. Indian J Pathol Oncol 2016;3(1):26-31

5. Poudel, A., Regmi, S., Poudel, S., \& Joshi, P. (2013). Correlation between Endoscopic and Histopathological Findings in Gastric Lesions. Journal of Universal College of Medical Sciences, 1(3), 37-41.

6. Dikshit RP, Mathur G, Mhatre S, Yeole BB. Epidemiological review of gastric cancer in India. Indian $\mathrm{J}$ Med Paediatr Oncol. 2011;32(1):3-11.

7. Akanda MR, Rahman AN. Comparative Study of Different Methods for Detection of Helicobacter Pylori in Gastric Biopsies. Dinajpur Med Col J 2011;4:1-6.

8. Bansal M, Kaur A, Bansal R. Prevalence of H. Pylori Infection in the Histopathological Spectrum of Gastric Lesions in Endoscopic Gastric Biopsies. IntJ Med Res Prof. 2017Sept;3(5):185-88. 
9. Sultana, A., Badruddoza, S., \& Rahman, F. (1). Correlation Between Endoscopic and Histological Findings in Different Gastroduodenal Lesion and its Association with Helicobacter Pylori; . Anwer Khan Modern Medical College Journal, 2(2), 6-10.

10. Suvarna N, Sasidharan VP. Histopathological and histogenetic study of carcinoma stomach in a high risk area. Indian J Cancer. 1995 Mar;32(1):36-42.

11. Correa P, Piazuelo MB, Wilson KT. Pathology of gastric intestinal metaplasia: clinical implications. Am J Gastroenterol. 2010;105(3):493-498.

12. Silva S, Filipe MI, Pinho A. Variants of intestinal metaplasia in the evolution of chronic atrophic gastritis and gastric ulcer. A follow up study. Gut. 1990 Oct;31(10):1097-104.

13. Thapa R, Lakhey M, Yadav PK, Kandel P, Aryal C, Subba K. Histopathological study of endoscopic biopsies. JNMA J Nepal Med Assoc. 2013 Apr-Jun;52(190):354-6.

14. Udoh MO, Obaseki DE. HISTOPATHOLOGICAL EVALUATION OF H. PYLORI ASSOCIATED GASTRIC LESIONS IN BENIN CITY, NIGERIA. East African Medical Journal. 2012 Dec;89(12):408-413.

15. Shanmugasamy K, Bhavani K, Vaithy AK, Narashiman R, Kotasthane DS. Clinical correlation of upper gastrointestinal endoscopic biopsies with histopathological findings and to study the histopathological profile of various neoplastic and non-neoplastic lesions. J Pharm Biomed Sci2016;06(03):220-224.

16. Dandin Archana S., Pawale Jayashree, Athanikar V.S..H.Pylori Associated Gastritis [Internet].2012 April [Cited February18, 2021];6(2):211-214.

17. Einstien D, Prathiba A, Parijatham BO, Maheswari K. Role of Mucin Histochemistry in Gastric Mucosal Lesions. Int J Sci Stud 2016;4(8):146-149.

18. Mandal PK, Chakrabarti S, Ray A, Chattopadhyay B, Das S. Mucin histochemistry of stomach in metaplasia and adenocarcinoma: An observation. Indian J Med Paediatr Oncol. 2013;34(4):229-233.

19. Rothery GA, Day DW. Intestinal metaplasia in endoscopic biopsy specimens of gastric mucosa. J Clin Pathol 1985;38:613-21.

20. Craanen ME, Blok P, Dekker W, Ferwerda J, Tytgat GN. Subtypes of intestinal metaplasia and Helicobacter pylori. Gut. 1992;33(5):597-600.

21. Quan S, Lin J, Jiang Z, H X, Sun C, Lin Z, Su T, Chen S, Si J. AB-PAS as a potential alternative for the diagnosis of intestinal metaplasia. Biomedical Research 2017; 28 (10): 4726-4729.

22. Correa P, Piazuelo MB, Wilson KT. Pathology of gastric intestinal metaplasia: clinical implications. Am J Gastroenterol. 2010;105(3):493-498.

23. Jass JR, Filipe MI. The mucin profiles of normal gastric mucosa, intestinal metaplasia and its variants and gastric carcinoma. Histochem J. 1981 Nov;13(6):931-9

24. Jass JR, Filipe MI. Sulphomucins and precancerous lesions of the human stomach. Histopathology. 1980 May;4(3):271-9.

25. Segura DI, Montero C. Histochemical characterization of different types of intestinal metaplasia in gastric mucosa. Cancer. 1983 Aug 1;52(3):498-503.

26. Rehman M, Chughtai NM, Hashmi SN, Jalil S, Riaz S (2016) Histochemical Detection of O-acetyl Sialomucin in Adenocarcinoma in Gastric Biopsies: An Old Mucin with New Perspective. J Cytol Histol 7: 420.

*Corresponding author:

Dr. Alankrita Deka, Swaraj Residency, Hengrabari road, Guwahati

Phone: +91 9401309171

Email: alankritadeka@gmail.com

Financial or other Competing Interests: None.

$\begin{array}{lr}\text { Date of Submission } & : 24 / 11 / 2020 \\ \text { Date of Final Revision } & : 18 / 02 / 2021 \\ \text { Date of Acceptance } & : 22 / 02 / 2021 \\ \text { Date of Publication } & : 30 / 03 / 2021\end{array}$ 